\title{
Evaluation of DNA Methylation of MAP9 Gene in Breast Cancer as Epigenetic Biomarker
}

\author{
Mina Dehbid ${ }^{1 *}$, Seyed Ahmad Aleyasin ${ }^{1}$ and Hamidreza Vaziri²
}

${ }^{1}$ Medical Biotechnology Division, National Institute of Genetic Engineering and Biotechnology (NIGEB), Iran

${ }^{2}$ Department of Biology, Faculty of Sciences, University of Guilan, Rasht, Iran

\begin{abstract}
Background: Recent findings indicate epigenetic modifications as key factors in breast carcinogenesis. The abnormal methylation patterns of genes are among the consequences of epigenetic changes. The DNA methylation is involved in the regulation of gene activity and abnormal DNA methylation is associated with various diseases, including cancer. Due to the importance of epigenetics in cancer, particularly breast cancer, it seems to perform the most effective methods of prediction, detection and tracking of recurrence, and the availability of suitable biomarkers. In this study, the MAP9 (Microtubule-Associated Protein 9) gene methylation was examined as an epigenetic biomarker of cancer.

Methods: We evaluated 30 breast cancer samples and 30 normal samples to identify diagnosis biomarkers for breast cancer. Sample of breast cancers were identified, with different Clinical and pathological data, which might be related with changes in MAP9 gene methylation. DNA was extracted from whole blood of breast cancer patients and healthy samples. The methylation-sensitive restriction enzymes were used to identify methylated site in epigenetic marker. Methylation-sensitive enzyme cannot cut hypermethylated sequences. Methylation-sensitive enzyme is not capable of cutting sequences of MAP9 gene, thus replication occurs.

Results: MAP9 gene is significantly hypermethylated in breast cancer $(P<0.05)$. Moreover the results of this study indicated that there was no relation between stage of disease, age of patients, Estrogen Receptor (ER), Progesterone Receptor (PR), and human epidermal growth factor 2 (HER2) status and the methylation of MAP9 gene in breast cancer samples $(P>0.05)$.

Conclusion: In this study indicated MAP9 gene methylation changes in breast cancer and it can be used as molecular biomarker for breast cancer diagnosis.
\end{abstract}

Keywords: Breast cancer; Methylation; MAP9 gene; Methylation sensitive restriction enzymes

\section{Introduction}

Cancer is abnormal cell divisions without control and ability to invade other tissues. Most cancers are named for the organ or type of cell in which they start [1]. Breast cancer is a type of cancer that starts in the breast tissue. The causes are unknown, although there are some evidence that epigenetic factors may be one of the risk factors for breast cancer [2].

The modern definition of epigenetics is the study of heritable changes in gene expression that are not caused by changes in DNA sequence [3]. DNA methylation of the epigenetic mechanisms involved in numerous phenomena such as parental imprinting, Growth and embryonic differentiation, $\mathrm{X}$ Chromosome inactivation and inhibition of gene transcription [4-6]. The methyl group $\left(\mathrm{CH}_{3}\right)$ is transfered from $\mathrm{S}$-adenosylmethionine (SAM) to CPG dinucleotide on the 5-carbon position of cytosine by methyltransferases [7]. DNA Methylation occurs in intragenic, intergenic, 5> gene upstream and 3> gene downstream regions, which create a pattern of DNA methylation in genome [8].

Many studies have shown that methylation pattern abnormalities lead to the creation of cancer [9], and hypermethylation and hypomethylation of DNA happen in early and developing stages of various types of cancers. They can be considered as epigenetic biomarker of cancer in the human DNA [10,11]. In other words, cancer biomarker refers to indication of the presence of cancer in the body [12]. In cancer research and medicine, usage of biomarkers is including: Diagnosis (to help diagnose conditions, as in the case of identifying early stage cancers); Prognosis (to indicate how aggressive a condition is, as in the case of determining a patient's ability to fare in the absence of treatment); Prediction (to predict how well a patient will respond to treatment) [13].

Genetics, epigenetics, proteomics and glycomics can be used for cancer biomarkers [12]. In this study, we examined the Microtubule-Associated Protein 9 (MAP9) gene methylation as an epigenetic biomarker of cancer. Human MAP9 gene is also called ASAP, which is located on chromosome $4 q 32.1$ and on the negative strand DNA [14]. The gene encodes MAP9 protein that it's C-terminal is associated with $\alpha$-tubulin at all phases of the cell cycle. MAP9 protein is required for spindle function, bipolar spindle assembly, mitotic progression, and cytokinesis. It may also serve to stabilize interphase microtubules [15-17].

Accurate transfer of genetic information plays essential roles for the survival of living organisms. DNA damage is induced by endogenous or exogenous factors. The tumor suppressor protein p53 is a central regulator of cell cycle arrest and apoptosis in the response to genotoxic stress. The inappropriate $\mathrm{p} 53$ activation is prevented through a network of tight controls in unstressed cells. The p53 protein is rapidly stabilized

*Corresponding author: Mina Dehbid, M.Sc, The National Institute of Genetic Engineering and Biotechnology, Shahrak-e Pajoohesh, km 15, Tehran - Karaj Highway, Tehran, Iran, P.O. Box: 14965/161, Tehran, Iran, Tel: (+98) 21 44787301-27 (+98) 21 44787396, 98 Fax: (+98) 2144787399 E-mail: Armina_amd@yahoo.com

Received December 31, 2015; Accepted January 28, 2016; Published January 30, 2016

Citation: Dehbid M, Aleyasin SA, Vaziri H (2016) Evaluation of DNA Methylation of MAP9 Gene in Breast Cancer as Epigenetic Biomarker. J Mol Biomarkers Diagn S8:015. doi:10.4172/2155-9929.S8-015

Copyright: (c) 2016 Mina Dehbid, et al. This is an open-access article distributed under the terms of the Creative Commons Attribution License, which permits unrestricted use, distribution, and reproduction in any medium, provided the original author and source are credited 
and activated by various mechanisms under stress conditions, and also these mechanisms including enhanced MDM2 degradation and posttranslational modifications of p53 and MDM2 [18-20]. In response to DNA damage, N-terminal domain of MAP9 interacts with p53 which it helps to stabilize p53, as well as increment in p53dependent transcription [21]. MAP9 stabilizes P53 by reducing MDM2 and also induction of p300-dependent p53 acetylation. MDM2 is an intermediate to ubiquitination and degradation of $\mathrm{p} 53$. Recent studies have shown that the MAP9 as a DDR component may participate in the regulation of P53-MDM2-P300 cycle (Figure 1) [22]. Heyn et al., has shown that there are high differences in methylation between normal and breast cancer samples in several genes such as MAP9. The map 9 gene methylation was investigated by Infinium DNA methylation Beadchip techniques. Moreover, this study demonstrated the MAP9 gene hypermethylation pattern in breast cancer [23]. Basbous, et al. (2014) examined on 26 patients with colorectal cancer. It has been demonstrated that low expression of map 9 is pathogenic and can be an important prognostic marker. Thus, the protein has the potential to be a tumor marker for colorectal cancer. In addition, this gene can be used as targets for the development of-cancer treatment methods [24].

\section{Materials and Methods}

\section{Sample collection}

Breast cancer is more common in females, so sampling was performed among women. In this regard, control samples were obtained from thirty healthy women. Breast cancer samples were from thirty women that were hospitalized at Imam Khomeini Hospital in 2013. Whole blood samples (Tubes containing EDTA) were collected from all cases before breast biopsy and stored at $-70^{\circ} \mathrm{C}$. Due to clinical factors such as age, stage of disease and bio-markers such as ER, PR and HER2 at evaluation of the clinical course, prognosis and also determination the type of treatment for breast cancer play a key role. Information of all patients for these factors was collected in order to assess their correlation to the results of the study. This research project was performed at the National Institute for Genetic Engineering and Biotechnology (NIGEB) in Tehran, Iran.

\section{DNA isolation}

DNA was extracted from $200 \mu$ of archived whole blood of each subject by MBST DNA extraction Kit. DNA purity and concentration are measured by Nano Drop ${ }^{\text {Tix }}$ spectrophotometer at a wavelength of $280 / 260 \mathrm{~nm}$.

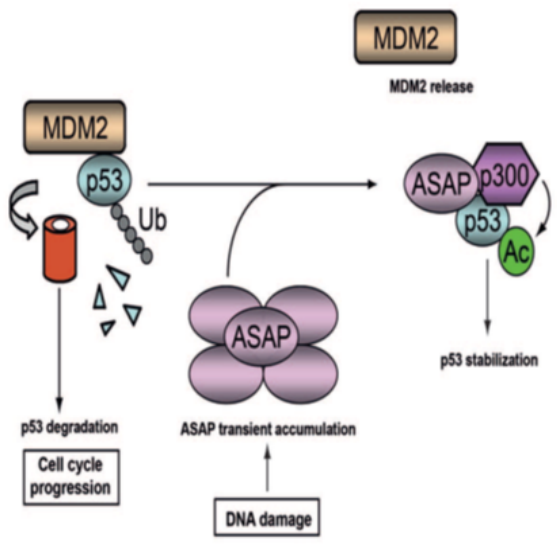

Figure 1: MAP9 signaling pathway; MAP9 in response to DNA damage, provides stabilization of P53 with two main pathway. MAP9 leads to reduction in the MDM2, and the other side, leads to the sta bilization of the p53 with p300mediated acetylation [22]

\section{Restriction endonuclease quantitative PCR (RE-PCR)}

A variety of methods have been described for detecting DNA with CPG island methylation changes in bodily fluids. Restriction endonuclease quantitative PCR method was used in this study [25]. This method makes it possible to quantify the amount of methylated DNA in each sample and to detect a methylated MAP9 allele.

Briefly, DNA was extracted from whole blood samples, digested with a methylation-sensitive enzyme, PmCa1. It recognizes CACGTG sequence and cuts the CAC $\downarrow$ GTG sequence, although cleavage site is blocked by methylation. It means that the enzyme does not cut the methylated form of $\mathrm{CA}^{5 \mathrm{~m}} \mathrm{CGTG}$ sequence. The DNA sample without $\mathrm{CA}^{5 \mathrm{~m}} \mathrm{CGTG}$, the DNA is cut thus PCR products were not detected after the amplification. $200 \mathrm{ng}$ of DNA was incubated at $37^{\circ} \mathrm{C}$ for overnight (To ensure complete digestion) with $0.5 \mu \mathrm{l}$ of restriction enzyme, 1 $\mu \mathrm{l}$ 10XL Buffer (Takara) and sterilized distilled water to give a final reaction volume of $10 \mu \mathrm{l}$.

For patients and control samples, PCR amplification was done on untreated DNA and DNA treated with the restriction enzyme PmCa1 (Takara) using the protocol. All PCR reactions were performed in a lightcycler ${ }^{\mathrm{TM}}$ system (Corbett Real-Time Thermal) using specific primer set (5'primer: 5'TAC AAT TCC AGG CAC TCT TCC A; 3'primer: 5' AGA ACC CTG TTT CCG ACT GC) which brackets one PmCal recognition sites.

PCR was performed with following these conditions: $95^{\circ} \mathrm{C}$ for 5 minutes followed by 35 cycles of $95^{\circ} \mathrm{C}$ for 45 seconds, $59.2^{\circ} \mathrm{C}$ for 30 seconds, $72^{\circ} \mathrm{C}$ for 30 seconds, and $72^{\circ} \mathrm{C}$ for 7 minutes. The $20 \mu \mathrm{l}$ reaction mixture, consisting of DNA ( $50 \mathrm{ng}), 0.5 \mu \mathrm{l}$ of forward and reverse primer ( $10 \mathrm{pmol} /$ $\mu \mathrm{l})$ and $10 \mu \mathrm{l}$ of Taq $2 \mathrm{x}$ master mix were used in PCR.

Real-Time PCR was performed with following these conditions: $95^{\circ} \mathrm{C}$ for 30 seconds followed by 40 cycles of $95^{\circ} \mathrm{C}$ for 5 seconds, $59.2^{\circ} \mathrm{C}$ for 30 seconds, and $72^{\circ} \mathrm{C}$ for 30 seconds. The $15 \mu \mathrm{l}$ reaction mixture, consisting of DNA ( $50 \mathrm{ng}$ ), $0.5 \mu \mathrm{l}$ of forward and reverse primer ( $5 \mathrm{pmol} /$ $\mu \mathrm{l})$ and $7.5 \mu \mathrm{l}$ of SYBR ${ }^{\star}$ Premix Ex Taq II (2X) were used in Real-Time PCR. In each reaction set, water blank used as a negative control. 4-fold dilution series (1-0.001 ng) of determined DNA concentrations (50 ng) was used to make a standard curve (interpolation to standard curves to create linear values). The initial amount of DNA was estimated by calculation of CT value derived from the standard curve. Methylation index was calculated as following:

Methylation index $=\{\mathrm{Ct}$ value of DNA which treated with PmCa1 $\}$ - $\{\mathrm{Ct}$ value of DNA which not treated with PmCa1\}.

\section{Statistical Analysis}

The primitive data from Real time RT-PCR analyzed with LinReg software which estimates the efficiency and Crossing Threshold (CT) for each reaction. The SPSS version 21.0 software (Chicago, SPSS Inc) was used for statistical analysis. Differences in CPG island methylation of MAP9 gene between 30 breast cancer samples and 30 normal samples were analyzed by T-test. It is done to assess the feasibility of using MAP9 methylation as a biomarker for the diagnosis of breast cancer in the blood. Information about stages of disease, age, PR, ER and Her 2 patients were collected, and their association to the MAP9 methylation was analyzed by One-Way Analysis of Variance (ANOVA). $P$ value $<0.05$ was accepted as a statistically significant. 
Citation: Dehbid M, Aleyasin SA, Vaziri H (2016) Evaluation of DNA Methylation of MAP9 Gene in Breast Cancer as Epigenetic Biomarker. J Mol Biomarkers Diagn S8:015. doi:10.4172/2155-9929.S8-015

Page 3 of 6

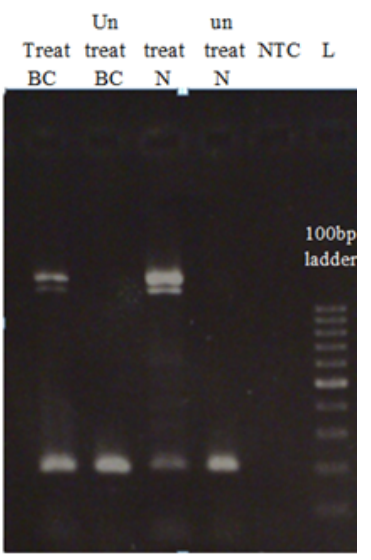

Figure 2: RE-PCR analysis of MAP9 gene methylation in normal samples and breast cancer samples. $1.8 \%$ agarose gel electrophoresis was used for MAP9 gene PCR products in treated and untreated breast cancer samples and normal samples with PmCa1 enzymes. L represents the $100 \mathrm{bp}$ Ladder and NTC is negative control. PCR products were shown in DNA treated with enzyme and DNA not treated with enzymes either in normal samples and breast cancer samples. It shows that treated DNA in breast cancer samples has more PCR products than treated DNA in normal samples. Thus the studied region in breast cancer is hypermethylated.

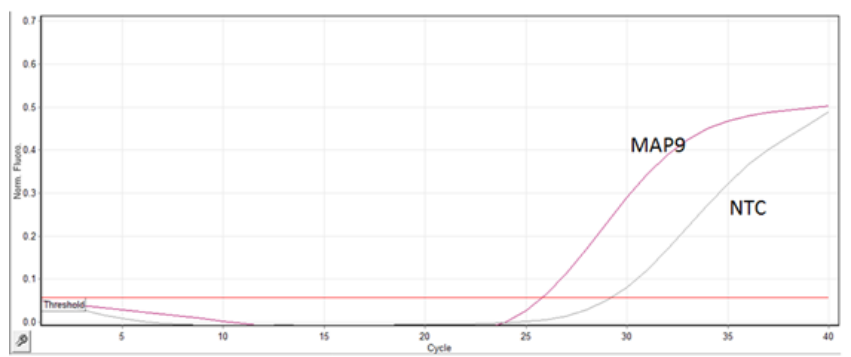

Figure 3: The amplification curves of MAP9 gene and negative control.

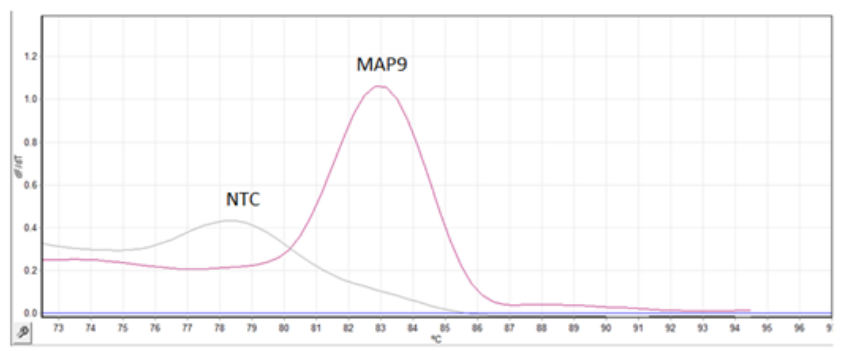

Figure 4: The melting curve of MAP9 gene and negative control.

\section{Results}

The difference in methylation between normal and breast cancer by PCR

Initially, equal amounts of extracted DNA (50 ng) from normal samples and breast cancer samples treated with PmCal enzymes. Then, treated DNA and untreated DNA with enzymes used as a template for PCR. In the case of methylation's study region, the enzyme is not able to cut it. PCR products were electrophoresed on a $1.8 \%$ agarose gel, stained with ethidium bromide, and photographed using Gel-doc system (Figure 2). Results of experimental study demonstrate hypermethylation of the study region in MAP9 gene for breast cancer patients.

\section{Real-time PCR validation}

Real-Time PCR is used to study more closely of MAP9 gene methylation and to find the difference in methylation between normal and breast cancer in RE-PCR technique. In order to perform quantification analysis of DNA for both treated MAP9 gene and untreated MAP9 gene, real-time PCR assay based on LightCycler technology and LinReg PCR software are used. Both amplification and melting curves are demonstrated for MAP9 gene with negative control in Figures 3 and 4. Moreover, the product of Real-Time PCR was verified for each reaction by electrophoresis (Figure 5).

MAP9 amplification was detected in all normal and breast cancer samples. Mean value comparison of $\Delta \mathrm{CT}$ (which is = treated-untreated) between normal and patient samples were statistically analyzed by using the SPSS software. A significant difference (P-value $<0.05)$ in MAP9 gene methylation was observed between patient and normal samples.

The $\Delta$ CT's mean value of the control group showed a greater amount than the patient group, so that gene amplification between enzyme-treated normal samples and enzyme-untreated normal samples is considerable.

Amplification discrepancy indicates differences in the amount of the enzymatic digestion in normal and breast cancer samples, owing to the fact that PmcAl enzyme is sensitive to methylation and methylated region prevents the enzyme cleavage. Lack of enzyme cleavage leads into gene amplification, thus enzyme cleavage decline indicates hypermethylation of the studied region in breast cancer (Figure 6).

\section{Clinical and Pathological Data}

The age range of normal samples was consisting of 18-59 years old person and the age range of breast cancer samples was 28-80 years old patients. Stage I (13.3\%), II (53.3\%) and III (33.3) were diagnosed by

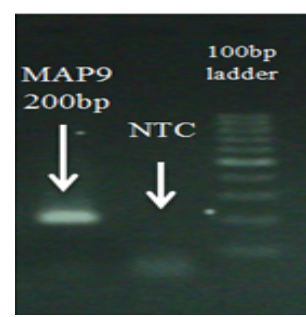

Figure 5: Real-time PCR product of MAP9 gene confirmed by electrophoresed on $1.8 \%$ agarose gel (Lane right to left: ladder 100bp, Negative control and 200bp MAP9, respectively).

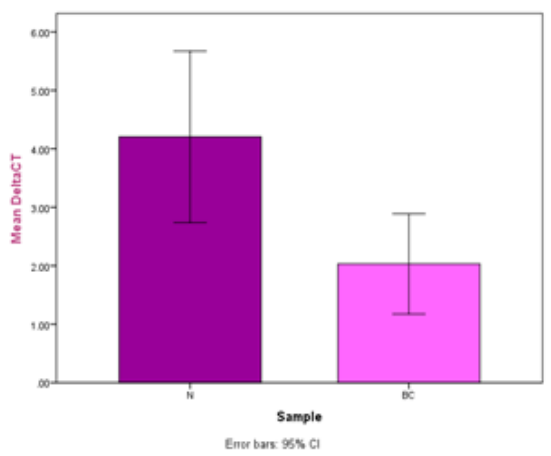

Figure 6: Mean comparison of $\triangle \mathrm{CT}$ between normal and breast cancer samples. There is significant difference between the two groups ( $P$-value $<0.05)$. 


\begin{tabular}{|c|c|}
\hline Clinic Pathological Features & Breast Cancer Patients (\%n) \\
\hline Age & $17(56.7)$ \\
\hline$\geq 50$ years & $13(43.3)$ \\
\hline Stage & $4(13.3)$ \\
\hline I & $16(53.3)$ \\
\hline II & $10(33.3)$ \\
\hline III & $19(63)$ \\
\hline Estrogen Receptor (ER) & $11(37)$ \\
\hline positive & \\
\hline negative & $18(60)$ \\
\hline Progesterone Receptor (PR) & $12(40)$ \\
\hline positive & \\
\hline negative & $15(50)$ \\
\hline Human Epidermal Growth Factor & $15(50)$ \\
\hline Receptor-2 (HER2) & \\
\hline positive & \\
negative & \\
\hline
\end{tabular}

Table 1: Data of clinic pathological features of 30 breast cancer patients.

pathology examination in the patients. Approximately, patients with breast cancer were 50\% HER2+, 63\% ER+, and 60\% PR+. Clinical and pathological data of the breast cancer patients are showed in Table 1.

\section{Association Between Clinic Pathological Factors and MAP9 Gene Methylation}

Study of association between clinic pathological factors and MAP9 gene methylation

In this research the possible relation between MAP9 gene methylation and clinic pathological factors such as age, stage of cancer, HER2, PR and ER were investigated. According to statistical analysis, no significant correlation was observed between $\triangle \mathrm{CT}$ and clinical factors in patients with breast cancer $(\mathrm{P}>0.05)$.

\section{Discussion}

Breast cancer is the most commonly detected cancer and the main reason of mortality from cancer among females, which is approximately $23 \%$ of the total cancers and $14 \%$ of the cancer deaths [26]. In addition, about 123,730 cases of breast cancers are expected to be diagnosed in 2015 [27]. Breast cancer is referred as the silent killer, due to the fact that in the early stages of breast cancer, breast pain and symptoms are usually not significant and sensible [28]. Subsequently, the use of indicative biomarkers of breast cancer in the early stages of the disease, could warn the person.

In order to improve the act of selecting the specific and individual treatments, predictive and prognostic biomarkers of cancer has been developing recently. Furthermore, the development of new methods for the detection of breast cancer is important because it lead to increase survival rate. Ideally, biomarkers obtained by non-invasive techniques which can collect biofluids such as blood. Discovery and use of blood-based epigenetic biomarkers are being developed. One of the reasons of performing blood tests is to identify tumors is that blood cells may have undergone epigenetic changes representative of those present in cancer [29].

In this study, the genomic DNA of white blood cells (i.e. whole blood) from normal samples and breast cancer samples was used based to explore the epigenetic biomarker in breast cancer on blood. The change of CPG region methylation of MAP9 gene in breast cancer was assessed by RE-PCR technique. RE-PCR is a simple two-step method for examining methylation of a region. In first stage, genomic DNA is digested by enzyme, then PCR is performed by primers surrounding region of enzyme recognition site [30,31]. Advantages of this approach include usage of low concentrations of DNA, low experiment steps, limited number of machines used, high accuracy and usage of commercially available enzymes.

According to the previous reports [23], the MAP9 gene in breast cancer showed significant changes in DNA methylation. Our study also showed MAP9 gene is significantly hypermethylated in breast cancer $(\mathrm{P}<0.05)$.

In this study the correlation between methylation of MAP9 gene and age of patients, disease stage, the status of the biomarkers such as, ER, PR, and HER2 in 30 breast cancers were evaluated [32].

\section{Stage of disease}

Molecular markers could have important applications in staging and the clinical diagnosis breast cancer [33]. Their Usage for cancer staging and personalization of treatment in time of diagnosis can improve patient care [34]. In this study, relation between methylation of MAP9 gene and stage of tumor was investigated and results revealed that the methylation of MAP9 gene was not correlated with the stage of the breast cancer $(\mathrm{P}>0.05)$.

\section{Age of patients}

The incidence rate of breast cancer increases with age. Seventy-nine percent of new cases and Eighty - Eight percent of death due to breast cancer happened in 50 years old women and older. Reduction of the incidence rate in eighty years old women and older, is probably due to the decrease in the rate of screening [35]. Data analysis in present study indicates no correlation between the methylation of MAP9 gene and age of patients in breast cancer samples $(\mathrm{P}>0.05)$.

\section{Breast cancer biomarkers/ER, PR, HER2}

One major role of pathology for assessment of breast cancer is specific biomarkers testes such as ER, PR, and HER2 status. These biomarkers can be used in prognosis and prediction [36].

HER2 test can indicate whether the sample is normal or sample has a large amount of protein HER 2 or whether copy number of HER2 gene is excessive. Furthermore, it will help to determine prognosis, situation of the tumor which is includes the aggression of the tumor and finally the best treatment options. Many of the breast cancer tumors contain ER and PR, that they can fuel the growth of breast cancer. Hormone-dependent breast cancer usually responds well to hormone therapy. Knowing whether the cancer cells have estrogen receptors or progesterone receptors can be beneficial to treatment plans [37]. The results of this study indicated that there was no relation between ER, PR, and HER2 status and the methylation of MAP9 gene in breast cancer samples $(\mathrm{P}>0.05)$. Further research in larger studied population may be needed to validate our results.

The findings illustrate the influence of MAP9 gene methylation in breast cancer and it can be used as molecular biomarker for breast cancer diagnosis. According to several studies, hyper methylation of genes can reduce their expression [38-41]. Therefore, the hyper methylation of MAP9 gene may lead to decreased of gene expression. It is possible that the decrease in expression of MAP 9 gene in cancer leads to instability of P53. Inhibition of apoptosis in cancer caused, following the non-stabilized P53 that is characteristic of cancer [19,20,22,42-45]. Our research is indicated MAP9 gene is significantly hypermethylated 
Citation: Dehbid M, Aleyasin SA, Vaziri H (2016) Evaluation of DNA Methylation of MAP9 Gene in Breast Cancer as Epigenetic Biomarker. J Mol Biomarkers Diagn S8:015. doi:10.4172/2155-9929.S8-015

in breast cancer; therefor it could be useful as a biomarker for breast cancer. Moreover our research indicated that there was no relation between stage of disease, age of patients, Estrogen Receptor (ER), Progesterone Receptor (PR), and human epidermal growth factor 2 (HER2) status and the methylation of MAP9 gene in breast cancer samples.

\section{Acknowledgements}

This study was supported by a National Institute of Genetic Engineering and Biotechnology (NIGEB(, Tehran, Iran. and University of Guilan, Rasht, Iran.

\section{References}

1. www.cancer.gov/about-cancer/what-is-cancer

2. Vo AT, Millis RM (2012) Epigenetics and breast cancers. Obstet Gynecol Int 2012: 602720 .

3. Slatkin M (2009) Epigenetic inheritance and the missing heritability problem. Genetics 182: 845-850.

4. Jaenisch R, Bird A (2003) Epigenetic regulation of gene expression: how the genome integrates intrinsic and environmental signals. Nat Genet 33 Suppl: 245-254

5. Esteller M (2008) Epigenetics in cancer. N Engl J Med 358: 1148-1159.

6. Berger SL, Kouzarides T, Shiekhattar R, Shilatifard A (2009) An operational definition of epigenetics. Genes \& development 23: 781-783.

7. Moore LD, Le T, Fan G (2013) DNA methylation and its basic function Neuropsychopharmacology 38: 23-38

8. Berger SL, Kouzarides T, Shiekhattar R, Shilatifard A (2009) An operational definition of epigenetics. Genes Dev 23: 781-783.

9. Yegnasubramanian S, Wu Z, Haffner MC, Esopi D, Aryee MJ, et al. (2011) Chromosome-wide mapping of DNA methylation patterns in normal and malignant prostate cells reveals pervasive methylation of gene-associated and conserved intergenic sequences. BMC genomics 12: 313

10. Lim DH, Maher ER (2010) Genomic imprinting syndromes and cancer. Adv Genet 70: 145-175

11. Esteller M (2008) Epigenetics in cancer. N Engl J Med 358: 1148-1159.

12. Pogribny IP (2010) Epigenetic events in tumorigenesis: putting the pieces together. Exp Oncol 32: 132-136.

13. Mishra A, Verma M (2010) Cancer biomarkers: are we ready for the prime time? Cancers (Basel) 2: 190-208.

14. Biomarkers in Cancer (2010) An Introductory Guide for Advocates, Research Advocacy Network.

15. Venoux M, Delmouly K, Milhavet O, Vidal-Eychenié S, Giorgi D, et al. (2008) Gene organization, evolution and expression of the microtubule-associated protein ASAP (MAP9). BMC Genomics 9: 406

16. Compton DA (2000) Spindle assembly in animal cells. Annual review of biochemistry 69: 95-114.

17. Karsenti E, Vernos I (2001) The mitotic spindle: a self-made machine. Science 294: 543-547.

18. Wittmann T, Hyman A, Desai A (2001) The spindle: a dynamic assembly of microtubules and motors. Nature cell biology 3: E28-E34

19. Zhao X, Yu J, Bu Y, Zheng D (2009) Application of all-coated long stem prosthesis associated with allograft in revision total hip arthroplasty. Zhongguo Xiu Fu Chong Jian Wai Ke Za Zhi 23: 781-783.

20. Moore LD, Le T, Fan G (2013) DNA methylation and its basic function. Neuropsychopharmacology 38: 23-38.

21. Marine JC, Francoz S, Maetens M, Wahl G, Toledo F, et al. (2006) Keeping p53 in check: essential and synergistic functions of Mdm2 and Mdm4. Cell Death Differ 13: 927-934.

22. Oren M (2003) Decision making by p53: life, death and cancer. Cell Death Differ 10: 431-442.

23. Toledo F, Wahl GM (2006) Regulating the p53 pathway: in vitro hypotheses, in vivo veritas. Nat Rev Cancer 6: 909-923.
24. Poyurovsky MV, Katz C, Laptenko O, Beckerman R, Lokshin M, et al. (2010) The $\mathrm{C}$ terminus of p53 binds the $\mathrm{N}$-terminal domain of MDM2. Nat Struct Mo Biol 17: 982-989.

25. Basbous J, Knani D, Bonneaud N, Giorgi D, Brondello JM, et al. (2012) Induction of ASAP (MAP9) contributes to p53 stabilization in response to DNA damage. Cell Cycle 11: 2380-2390

26. Heyn H, Carmona FJ, Gomez A, Ferreira HJ, Bell JT, et al. (2013) DNA methylation profiling in breast cancer discordant identical twins identifies DOK7 as novel epigenetic biomarker. Carcinogenesis 34: 102-108.

27. Rouquier S, Pillaire MJ, Cazaux C, Giorgi D (2014) Expression of the microtubule-associated protein MAP9/ASAP and its partners AURKA and PLK1 in colorectal and breast cancers. Dis Markers 2014: 798170.

28. Lee WH, Isaacs WB, Bova GS, Nelson WG (1997) CG island methylation changes near the GSTP1 gene in prostatic carcinoma cells detected using the polymerase chain reaction: a new prostate cancer biomarker. Cancer Epidemiology Biomarkers \& Prevention 6: 443-450.

29. Jemal A, Bray F, Center MM, Ferlay J, Ward E, et al. (2011) Global cancer statistics. CA Cancer J Clin 61: 69-90.

30. Siegel RL, Miller KD, Jemal A (2015) Cancer statistics, 2015. CA Cancer J Clin 65: 5-29.

31. http://www.rightdiagnosis.com/disease/symptoms.htm

32. Bock C (2009) Epigenetic biomarker development. Epigenomics 1: 99-110. 201.

33. Nakayama M, Gonzalgo ML, Yegnasubramanian S, Lin X, De Marzo AM, et al. (2004) GSTP1 CpG island hypermethylation as a molecular biomarker for prostate cancer. J Cell Biochem 91: 540-552.

34. Bastian PJ, Palapattu GS, Lin X, Yegnasubramanian S, Mangold LA, et al. (2005) Preoperative serum DNA GSTP1 CpG island hypermethylation and the risk of early prostate-specific antigen recurrence following radical prostatectomy. Clinical Cancer Research 11: 4037-4043.

35. Joensuu K, Leidenius M, Kero M, Andersson LC, Horwitz KB, et al. (2013) ER, PR, HER2, Ki-67 and CK5 in Early and Late Relapsing Breast Cancer-Reduced CK5 Expression in Metastases. Breast Cancer (Auckl) 7: 23-34.

36. Ludwig JA, Weinstein JN (2005) Biomarkers in cancer staging, prognosis and treatment selection. Nat Rev Cancer 5: 845-856.

37. Rick Alteri, Cammie Barnes, Adriane Burke, Ted Gansler, Susan Gapstur, et al. (2013) Breast Cancer Facts \& Figures 2013-2014. American Cancer.

38. http://pathology.jhu.edu/breast/biomarker-testing.php

39. http://www.nationalbreastcancer.org/breast-cancer-lab-tests

40. Wagner JR, Busche S, Ge B, Kwan T, Pastinen T, et al. (2014) The relationship between DNA methylation, genetic and expression inter-individual variation in untransformed human fibroblasts. Genome Biol 15: R37.

41. Wajed SA, Laird PW, DeMeester TR (2001) DNA methylation: an alternative pathway to cancer. Ann Surg 234: 10-20.

42. Du L, Xie Z, Wu LC, Chiu M, Lin J, et al. (2012) Reactivation of RASSF1A in breast cancer cells by curcumin. Nutr Cancer 64: 1228-1235.

43. Choi SW, Friso S (2010) Epigenetics: A New Bridge between Nutrition and Health. Adv Nutr 1: 8-16.

44. Marine JC, Francoz S, Maetens M, Wahl G, Toledo F, et al. (2006) Keeping p53 in check: essential and synergistic functions of Mdm2 and Mdm4. Cell Death Differ 13: 927-934.

45. Poyurovsky MV, Katz C, Laptenko O, Beckerman R, Lokshin M, et al. (2010) The $\mathrm{C}$ terminus of $\mathrm{p} 53$ binds the N-terminal domain of MDM2. Nat Struct Mol Biol 17: 982-989.

This article was originally published in a special issue, Potential Biomarkers and Therapeutic Targets in Cancer Stem Cells handled by Editor(s). Dr. Murielle Mimeault, University of Nebraska Medical Center, USA 